\title{
Books Received / Livres reçus
}

Ardissino, Erminia, and Élise Boillet, eds. Gli Italiani e la Bibbia nella prima età moderna. Leggere, interpretare, riscrivere. Collection Études Renaissants. Turnhout: Brepols, 2018. Pp. $299+12$ b/w ill. and 3 colour ill. ISBN 9782-503-58406-5 (paperback) €50.

Buzzetta, Flavia. Magia naturalis e scientia cabalae in Giovanni Pico della Mirandola. Studi pichiani 20. Florence: Leo S. Olschki, 2019. Pp. x, 342. ISBN 978-88-8222-6630-9 (paperback) €35.

Chayes, Evelien, éd. Renaissance et ascensions de l'âme. De la lanterne à la lune, de la lune au soleil. Rencontres 327. Paris: Classiques Garnier, 2019. 206 p. +9 ill. b/n. ISBN 978-2-406-07399-4 (broché) 29€.

Chesney Zegura, Elizabeth. Marguerite de Navarre's Shifting Gaze: Perspectives on Gender, Class, and Politics in the Heptaméron. London: Routledge, Taylor \& Francis Group, 2017. Pp. viii, 276. ISBN 978-1-4724-8730-8 (hardcover) US\$124.

Donlan, Thomas A. The Reform of Zeal: François de Sales and Militant French Catholicism. St. Andrews Studies in French History and Culture 9. St. Andrews: Centre for French History and Culture of the University of St. Andrews, 2018. Pp. iv, 144. ISBN 978-1-907548-16-1 (paperback) n.p.

Ferrer, Véronique, Olivier Millet et Alexandre Tarrête, éds. La Renaissance au grand large. Mélanges en l'honneur de Frank Lestringant. Travaux d'Humanisme et Renaissance 600. Genève: Droz, 2019. 857 p. ISBN 9782-600-05832-2 (broché) 98 CFH.

Honig, Elizabeth Alice. Pieter Bruegel and the Idea of Human Nature. London: Reaktion Books, 2019. Pp. $269+68$ ill. ISBN 978-1-7891-4076-7 (hardcover) $£ 15.95$.

Huebert, Ronald, and David McNeil, eds. Early Modern Spectatorship: Interpreting English Culture, 1500-1780. Montreal and Kingston: McGill-Queen's University Press, 2019. Pp. xiv, $414+44$ ill. ISBN 978-0-7735-5677-5 (paperback) \$39.95.

Leong, Elaine. Recipes and Everyday Knowledge: Medicine, Science, and the Household in Early Modern England. Chicago: University of Chicago Press, 2018. Pp. $288+19$ ill. ISBN 978-0-2265-8366-2 (paperback) US $\$ 32.50$. 
Magnusson, Lynne, with David Schlkwyk, eds. The Cambridge Companion to Shakespeare's Language. Cambridge: Cambridge University Press, 2019. Pp. xiii, 293. ISBN 978-1-107-58318-4 (paperback) \$28.95.

Mattison, Andrew. Solitude and Speechlessness: Renaissance Writing and Reading in Isolation. Toronto: University of Toronto Press, 2019. Pp. v, 260. ISBN 978-1-4875-0404-5 (hardcover) \$75.

Mori, Elisabetta, ed. Lettere tra Paolo Giordano Orsini e Isabella de' Medici (1556-1576). In appendice lettere a Isabella dai fratelli, da sovrani, principi, ambasciatori e altri. Rome: Gangemi Editore, 2019. Pp. $478+15$ b/w ill. ISBN 978-8-8492-3721-4 (paperback) €40.

Murphy, Peter. The Long Public Life of a Short Poem: Reading and Remembering Thomas Wyatt. Stanford: Stanford University Press, 2019. Pp. xvii, $246+$ 50 b/w ill. ISBN 978-1-5036-0928-0 (paperback) US\$28.

Puljcan Juric, Lea. Illyria in Shakespeare's England. Madison / Teaneck: Fairleigh Dickinson University Press, 2019. Pp. $353+12$ ill. ISBN 978-168393-176-8 (hardcover) US $\$ 115$.

Quiviger, François. Leonardo da Vinci: Self, Art and Nature. London: Reaktion Books, 2019. Pp. $221+71$ colour ill. ISBN 978-1-78914-070-5 (hardcover) $£ 15.95$.

Roudaut, François et Jean-François Stoffel, éds. Le Soleil à la Renaissance et à l'âge classique. Actes, enrichis de contributions supplémentaires, de la journée d'études tenue à l'Université Paul-Valéry - Montpellier 3 (20 novembre 2015). Numéro spécial de Revue des Questions Scientifiques 198.4 (2018): 369-630.

Schotte, Margaret E. Sailing School: Navigating Science and Skill, 1550-1800. Baltimore: Johns Hopkins University Press, 2019. Pp. xi, $297+79$ ill. ISBN 978-1-4214-2953-3 (hardcover) US\$59.95.

Terpstra, Nicholas ed. Lives Uncovered: A Sourcebook of Early Modern Europe. Toronto: University of Toronto Press, 2019. Pp. xi, $288+28$ ill. ISBN 9781-4875-9451-0 (hardcover) \$59.95.

Walter, Melissa Emerson. The Italian Novella and Shakespeare's Comic Heroines. Toronto: University of Toronto Press, 2019. Pp. xiii, 279. ISBN 9781-4875-0364-2 (hardcover) \$65.

Warren, Nancy Bradley. Chaucer and Religious Controversies in the Medieval and Early Modern Eras. Notre Dame: University of Notre Dame Press, 2019. Pp. xiii, 213. ISBN 978-0-268-10582-2 (paperback) US $\$ 45$. 
Wood, Christopher S. A History of Art History. Princeton: Princeton University Press, 2019. Pp. $459+24$ b/w ill. ISBN 978-0-691-15652-1 (hardcover) US\$ 29.95. 